Check for updates

Cite this: RSC Adv., 2017, 7, 35897

\title{
General fabrication and enhanced VOC gas-sensing properties of hierarchically porous metal oxides $\dagger$
}

\author{
Yue Gao, ainghong Kong, *a Junhao Zhang ${ }^{b}$ and Guangcheng Xi (D) *c
}

Received 19th June 2017

Accepted 9th July 2017

DOI: $10.1039 / c 7 r a 06808 \mathrm{e}$

rsc.li/rsc-advances

\begin{abstract}
A facile and general route to synthesize hierarchically porous metal oxide nanostructures was reported here. The results indicate that the hierarchically porous metal oxides show high sensitivity to toxic or dangerous gases. The signal sensitivity of the gas sensors exhibits a good linear relation with the VOC gas concentration. As one of the as-synthesized hierarchically porous metal oxides, ZnO exhibits the lowest detection limit of $15 \mathrm{ppb}$ for formaldehyde, which is much lower than the limit value of indoor formaldehyde (60 ppb). Furthermore, the sensitivity of the $\mathrm{ZnO}$ porous nanosheets decorated with $\mathrm{Au}$ nanoparticles is $10 \mathrm{ppb}$ for formaldehyde, which is about 1.5 times higher than that of the unmodified ZnO porous nanosheets.
\end{abstract}

\section{Introduction}

Gas sensors have a wide range of applications in the fields of environmental quality monitoring, industrial production and indoor gas detection, and play an increasingly important role in both production activities and daily life. ${ }^{1-4}$ Among them, metal oxide gas sensors possess obvious advantages such as rapid responsiveness, low cost, high sensitivity and long service life, and account for $60 \%$ of gas sensors on the market. ${ }^{5-8}$ Previous studies have shown that metal oxide gas sensors have better sensing performance in the detection of volatile organic compounds (VOC). ${ }^{9-11}$ In order to obtain greater gas-sensing properties, like high sensitivity, fast response and rapid recovery, most research focused on improving the gas-sensing properties of metal oxide materials includes three aspects, namely, a nanostructure, a hierarchically porous structure, and noble-metal surface modification. ${ }^{12-14}$ Through the above three measures, the film will display a higher sensitivity, due to its very large specific surface area, which provides more gas channels and improves the utilization of the material. In addition, a hierarchically porous structure can offer more surface active sites that allow the material to contact the target gas directly, which not only increases physical and chemical adsorption, but also greatly shortens the response and recovery time..$^{15,16}$

${ }^{a}$ School of the Environment and Safety Engineering, Jiangsu University, Zhenjiang, 212013, P. R. China.E-mail: kongqh@mail.ujs.edu.cn

${ }^{b}$ School of the Environment and Chemical Engineering, Jiangsu University of Science and Technology, Zhenjiang, 212013, P. R. China

'Institute of Industrial and Consumer Product Safety, Chinese Academy of Inspection and Quarantine, Beijing 100176, P. R. China. E-mail: xiguangcheng@caiq.gov.cn

$\dagger$ Electronic supplementary information (ESI) available. See DOI: 10.1039/c7ra06808e
Among a large number of semiconductor metal oxides, $\mathrm{Co}_{3} \mathrm{O}_{4}, \mathrm{ZnO}$ and $\mathrm{NiO}$ are significant gas-sensitive materials due to their high sensitivity, low cost and strong operability. ${ }^{17-19}$ To date, many porous structures of these three metal oxides have been synthesized. However, there are few reports on the use of a facile and general method to synthesize their hierarchically porous structures. As we all know, complex synthesis methods increase experimental costs, and may also produce a lot of toxic and harmful substances, which is not conducive to laboratory experiments and industrial production. ${ }^{20-22}$ Therefore, using a facile and general method to synthesize $\mathrm{Co}_{3} \mathrm{O}_{4}, \mathrm{ZnO}$ and $\mathrm{NiO}$ with hierarchically porous structures has offered hope towards solving this problem. In order to enhance strong points and avoid weaknesses, the use of a convenient synthesis method to obtain high performance gas-sensing materials has become extremely essential and urgent.

In this study, we present a facile and general route to fabricate hierarchically porous metal oxide materials and modify their surfaces with a noble-metal using a two-step method. According to this design, sensitive materials such as $\mathrm{Co}_{3} \mathrm{O}_{4}, \mathrm{ZnO}$ and $\mathrm{NiO}$ were utilized in the manufacture of gas sensors to detect VOCs, such as alcohol, acetone, methyl alcohol, formaldehyde and $n$-butanol. After decorating with Au nanoparticles, better gas-sensing properties were obtained, especially in relation to high sensitivity, fast response and shortened recovery time, demonstrating that our method is an effective strategy to enhance the gas performance of materials.

\section{Experimental}

\section{Materials}

The materials used in this experiment were all of analytical grade and used directly without further purification. $\mathrm{HAuCl}_{4}{ }^{-}$ $\cdot 4 \mathrm{H}_{2} \mathrm{O}$ was purchased from Sinopharm Chemical Reagent Co., 
Ltd. $\mathrm{Co}\left(\mathrm{CH}_{3} \mathrm{CO}_{2}\right)_{2} \cdot 4 \mathrm{H}_{2} \mathrm{O}, \mathrm{Zn}\left(\mathrm{NO}_{3}\right)_{2}, \mathrm{Ni}\left(\mathrm{CH}_{3} \mathrm{COO}\right)_{2} \cdot 4 \mathrm{H}_{2} \mathrm{O}$ and $\mathrm{H}_{2} \mathrm{NCONH}_{2}$ were obtained from Shantou Xilong Chemical Factory.

\section{Synthesis of the hierarchically porous metal oxides}

The synthetic processes were performed using a two-step synthesis method. Step one involved the synthesis of three precursors using a hydrothermal method. Step two was the calcination of the as-synthesized precursors in order to obtain a porous structure. During the synthesis procedure of the precursors, $25 \mathrm{~mL}$ of $0.4 \mathrm{~mol} \mathrm{~L}^{-1} \mathrm{Co}\left(\mathrm{CH}_{3} \mathrm{CO}_{2}\right)_{2} \cdot 4 \mathrm{H}_{2} \mathrm{O}$ or $25 \mathrm{~mL}$ of $0.4 \mathrm{~mol} \mathrm{~L}^{-1} \mathrm{Zn}\left(\mathrm{NO}_{3}\right)_{2}$ was added into $50 \mathrm{~mL}$ of $0.8 \mathrm{~mol} \mathrm{~L}^{-1} \mathrm{H}_{2} \mathrm{NCONH}_{2}$. Each of the two solutions was placed in a beaker under stirring for 30 minutes and then the mixtures were moved to Teflon-lined stainless-steel autoclaves. These two chemical reactions were allowed to proceed in the autoclaves for 10 hours at a constant temperature of $100{ }^{\circ} \mathrm{C}$. To synthesize the third material, $10 \mathrm{~mL}$ of $0.4 \mathrm{~mol} \mathrm{~L}^{-1}$ $\mathrm{Ni}\left(\mathrm{CH}_{3} \mathrm{COO}\right)_{2} \cdot 4 \mathrm{H}_{2} \mathrm{O}$ and $10 \mathrm{~mL} \mathrm{HOCH}_{2} \mathrm{CH}_{2} \mathrm{NH}_{2}$ were dissolved in $34 \mathrm{~mL} \mathrm{H}_{2} \mathrm{O}$. The mixed solution was maintained in another autoclave at $120{ }^{\circ} \mathrm{C}$ for 64 hours. After that, the three obtained precipitates were washed 3 times with deionized water and dried at $60{ }^{\circ} \mathrm{C}$ for 30 minutes in order to collect the precursors, namely, $\mathrm{Co}\left(\mathrm{CO}_{3}\right)_{0.5}(\mathrm{OH})_{0.1} \cdot \mathrm{H}_{2} \mathrm{O}, \mathrm{Zn}_{5}\left(\mathrm{CO}_{3}\right)_{2}(\mathrm{OH})_{6}$ and $\mathrm{Ni}(\mathrm{OH})_{2}$, in order. Finally, the hierarchically porous $\mathrm{Co}_{3} \mathrm{O}_{4}, \mathrm{ZnO}$ and $\mathrm{NiO}$ materials were acquired by calcining the precursors from room temperature to $400{ }^{\circ} \mathrm{C}$, raised at a ramp rate of $1^{\circ} \mathrm{C} \min ^{-1}$ and kept at the target temperature for 80 minutes.

\section{Surface modification of hierarchically porous metal oxides with Au nanoparticles}

The surface modification of the hierarchical structures was carried out using a one-step hydrothermal reaction. For the three reactions, $0.1 \mathrm{~g}$ of $\mathrm{Co}\left(\mathrm{CO}_{3}\right)_{0.5}(\mathrm{OH})_{0.1} \cdot \mathrm{H}_{2} \mathrm{O}, \mathrm{Zn}_{5}\left(\mathrm{CO}_{3}\right)_{2}$ $(\mathrm{OH})_{6}$, or $\mathrm{Ni}(\mathrm{OH})_{2}$ was placed in a mixture of $10 \mathrm{~mL}$ deionized water and $3 \mathrm{~mL} 1 \mathrm{mg} \mathrm{mL}{ }^{-1} \mathrm{HAuCl}_{4} \cdot 4 \mathrm{H}_{2} \mathrm{O}$ solution. For the purpose of achieving good mixing uniformity, the solutions were stirred at room temperature for 4 hours and preserved in three Teflon-lined stainless-steel autoclaves at $120^{\circ} \mathrm{C}$ for 1 hour. After washing and drying, the precursors were calcined from room temperature to $400{ }^{\circ} \mathrm{C}$ and kept at $400{ }^{\circ} \mathrm{C}$ for 80 minutes. Finally, the $\mathrm{Co}_{3} \mathrm{O}_{4}, \mathrm{ZnO}$ and $\mathrm{NiO}$ decorated with $\mathrm{Au}$ nanoparticles were obtained.

\section{Characterization}

The samples in the experiment were characterized using X-ray diffraction (XRD) on a Bruker D8 Focus diffractometer. The Xray tubes were operated with an electric current of $40 \mathrm{~mA}$ and a voltage of $40 \mathrm{kV}$. The morphology of the precursors and final products was obtained using scanning electron microscopy (SEM Hitachi S4800) and transmission electron microscopy (TEM FEI F30). The pore features were analyzed using a Brunauer-Emmett-Teller $\mathrm{N}_{2}$ adsorption and desorption experiment (BET micromeritics TriSta) and thermo-gravimetric analysis (TG Mettler Toledo TGA/DCS1), with a heating speed of
$10{ }^{\circ} \mathrm{C} \min ^{-1}$ in $\mathrm{N}_{2}$. The sensing properties were surveyed using a sensing measurement system (Winsen Electronics Co. Ltd. WS-30A) at a relative humidity of about $25 \%$.

\section{Fabrication and sensing measurements of the gas sensors}

In order to certify the sensing performance, gas sensors were constructed using the following procedure. The metal oxide powers, which served as the sensing materials, were ground to coat onto a ceramic tube. Then the devices were calcined at $460{ }^{\circ} \mathrm{C}$ for 3 days, to enhance their stability in the following experiments. The best operating temperature of each material was found through preliminary experiments. Then the gas sensors were exposed to the target gases in turn, to obtain the relevant experimental data.

\section{Results and discussion}

\section{Morphology and structure characterization}

As shown in Fig. 1a, the XRD patterns of the three precursors reveal that they belong to $\mathrm{Co}\left(\mathrm{CO}_{3}\right)_{0.5}(\mathrm{OH})_{0.1} \cdot \mathrm{H}_{2} \mathrm{O}$ (JCPDS card
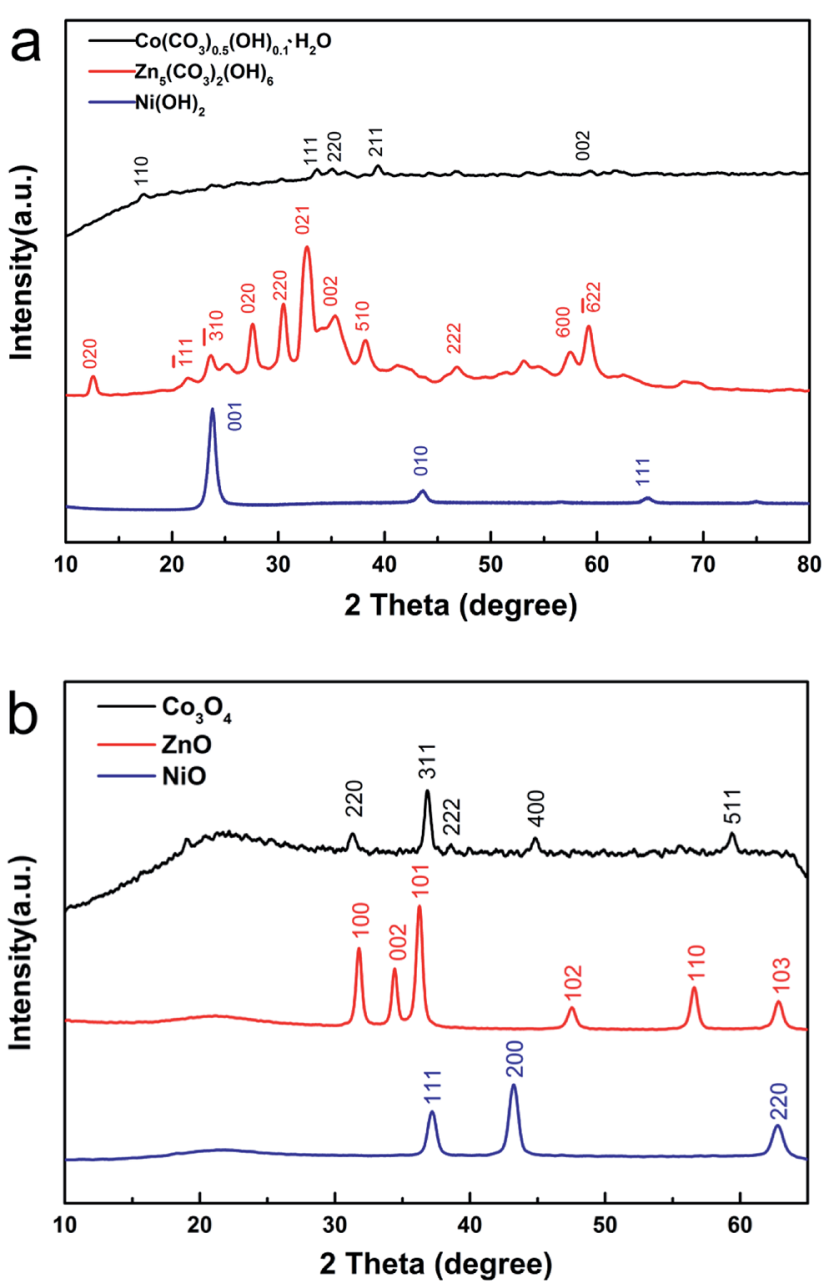

Fig. 1 (a) XRD patterns of the precursors $\mathrm{Co}\left(\mathrm{CO}_{3}\right)_{0.5}(\mathrm{OH})_{0.1} \cdot \mathrm{H}_{2} \mathrm{O}$, $\mathrm{Zn}_{5}\left(\mathrm{CO}_{3}\right)_{2}(\mathrm{OH})_{6}$ and $\mathrm{Ni}(\mathrm{OH})_{2}$. (b) XRD patterns of as-synthesized $\mathrm{CO}_{3} \mathrm{O}_{4}, \mathrm{ZnO}$ and $\mathrm{NiO}$, achieved by annealing the precursors. 
no. 48-0083), $\mathrm{Zn}_{5}\left(\mathrm{CO}_{3}\right)_{2}(\mathrm{OH})_{6}$ (JCPDS card no. 19-1458) and $\mathrm{Ni}(\mathrm{OH})_{2}$ (JCPDS card no. 73-6824). The data show that the precursors were successfully synthesized in the hydrothermal reaction. After annealing from room temperature to $400{ }^{\circ} \mathrm{C}$, the XRD patterns of the three final products were recorded, as shown in Fig. 1b. No other material characteristic peaks were detected. The characteristic peaks of the three metal oxides correspond to JCPDS card no. 78-1970, JCPDS card no. 715960 and JCPDS card no. 71-6743, indicating that the products $\mathrm{Co}_{3} \mathrm{O}_{4}, \mathrm{ZnO}$ and $\mathrm{NiO}$ were obtained using this general method.

The morphologies and structures of the obtained products were detected using SEM, TEM and HRTEM. In Fig. $2 \mathrm{a}_{1}-\mathrm{a}_{4}$, there are a great many superfine porous nanowires making up the $\mathrm{Co}_{3} \mathrm{O}_{4}$ flower-like architecture. Careful observation found that the average diameter of the porous nanowires is below $10 \mathrm{~nm}$. Furthermore, they are dense in their pore distributions. The porous $\mathrm{ZnO}$ flowers are shown in Fig. $2 \mathrm{~b}_{1}-\mathrm{b}_{4}$. Evidently, the ZnO flowers have specific hierarchically structural features. They all consist of thin sheets and there is a greater number of pores of different sizes distributed on the surface of each sheet. The average diameter of these pores is about $20-40 \mathrm{~nm}$. In addition, the thickness of the nanosheet is around $15 \mathrm{~nm}$, which can be seen from Fig. S1.† Fig. $2 c_{1}$ is the lowmagnification SEM image of the porous NiO flowers, which shows that the sample is made up of a huge number of hierarchical sheet structures. It can be observed that the sizes of the $\mathrm{NiO}$ flowers are uniform and their diameters are around $10 \mu \mathrm{m}$. Fig. $2 \mathrm{c}_{2}$ exhibits the porous features of the NiO nanosheets clearly and more detailed porous structural features can also be seen in Fig. $2 c_{3}$ and $c_{4}$.

From the standpoint of morphology, structure, reagent source and synthesis strategy, $\mathrm{Co}_{3} \mathrm{O}_{4}, \mathrm{ZnO}$ and $\mathrm{NiO}$ have several things in common. (1) The chemical materials used in the experiments are common reagents that can be purchased easily. Furthermore, the main materials in the syntheses are all general metal salts, so they are very cheap. (2) The precursors are all basic carbonates or hydroxide. In accordance with the stated method, the synthesis procedure of these precursors does not require high experimental temperatures, which saves energy. During this process, no poisonous and harmful gases are generated, so it is suitable for both laboratory research and industrial production in batch. (3) The final products are all composed of secondary structures, showing potential applications in other research areas, such as sewage treatment and drug loading. Furthermore, the pores placed on the secondary structures are dense, which can provide more gas channels, offering the possibility of higher sensitivity and a quicker response.
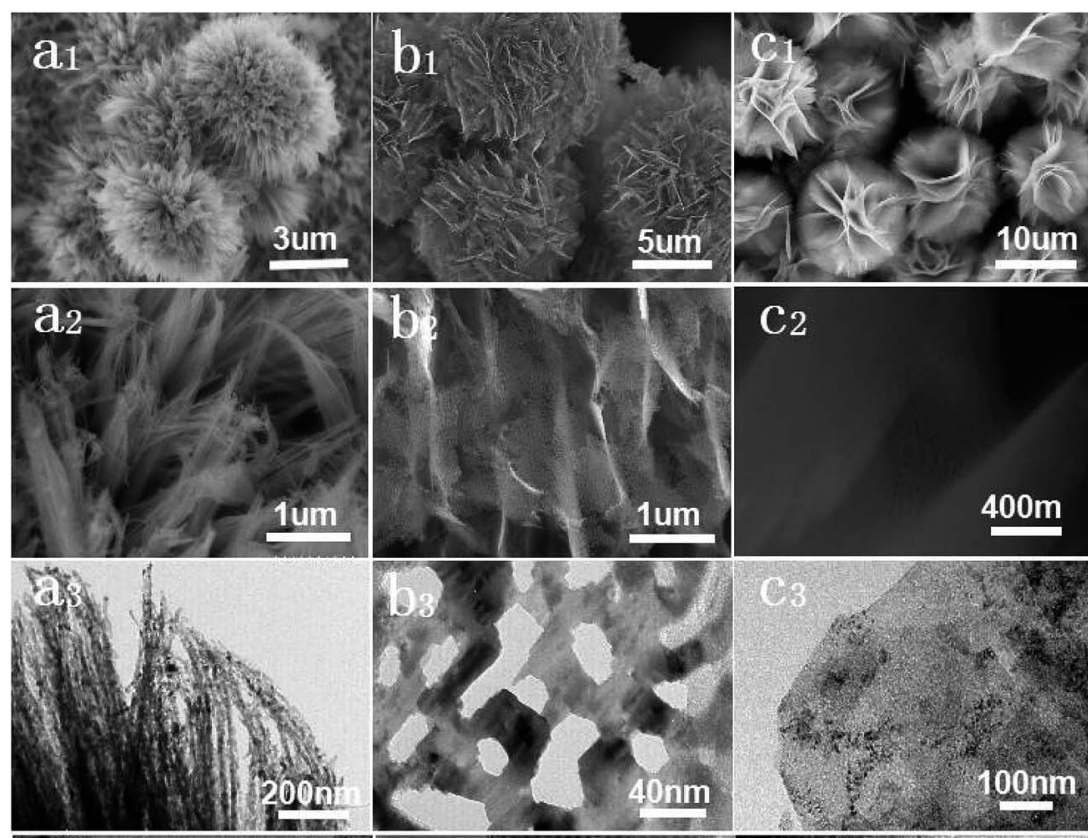

\section{C2}
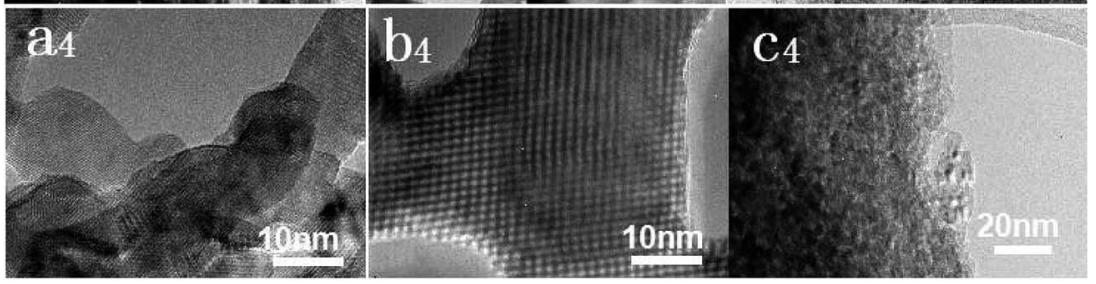

Fig. 2 SEM, TEM and HRTEM images of the as-synthesized $\left(a_{1}-a_{4}\right) \mathrm{Co}_{3} \mathrm{O}_{4}$ flower-like structures with porous nanowires, $\left(b_{1}-b_{4}\right) \mathrm{ZnO}$ porous nanosheets, and $\left(c_{1}-c_{4}\right) \mathrm{NiO}$ porous nanosheets. The images above clearly show the porous and hierarchical characteristics of the prepared samples. 


\section{Formation mechanism of the pores}

The thermo-gravimetric (TG) curves of $\mathrm{Co}\left(\mathrm{CO}_{3}\right)_{0.5}(\mathrm{OH})_{0.1} \cdot \mathrm{H}_{2} \mathrm{O}$, $\mathrm{Zn}_{5}\left(\mathrm{CO}_{3}\right)_{2}(\mathrm{OH})_{6}$ and $\mathrm{Ni}(\mathrm{OH})_{2}$ can be seen in Fig. 3. We can clearly see that the overall trend of the three TG curves is similar. Their weight loss can be divided into three stages from room temperature to $700{ }^{\circ} \mathrm{C}$. The first weight loss of less than $5 \%$ occurred

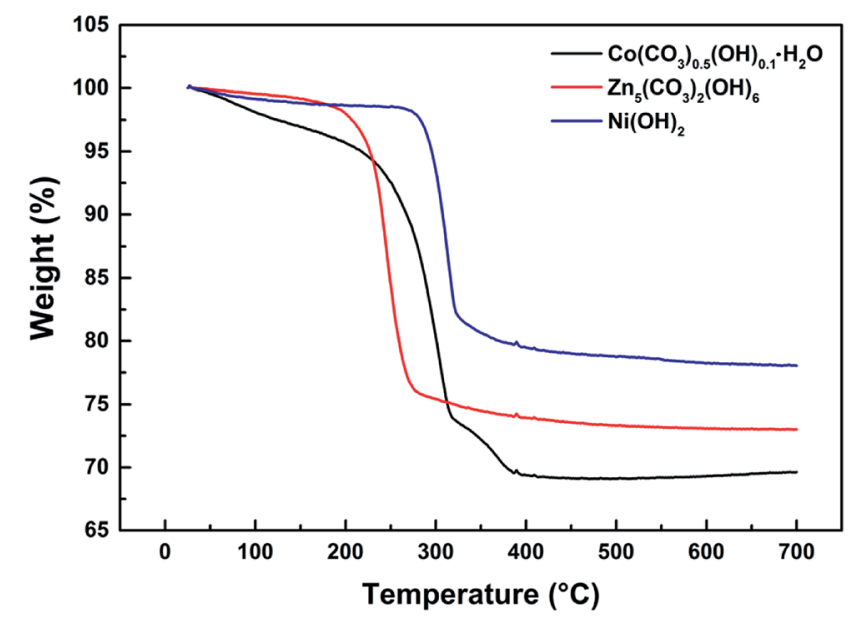

Fig. 3 TG curves of the precursors $\mathrm{Co}\left(\mathrm{CO}_{3}\right)_{0.5}(\mathrm{OH})_{0.1} \cdot \mathrm{H}_{2} \mathrm{O}, \mathrm{Zn}_{5}$ $\left(\mathrm{CO}_{3}\right)_{2}(\mathrm{OH})_{6}$ and $\mathrm{Ni}(\mathrm{OH})_{2}$. between 50 and $200{ }^{\circ} \mathrm{C}$. This weight loss is mainly due to the thermal evaporation of water bound to the surfaces of the precursors. The second stage of weight loss occurred from 200 to $400{ }^{\circ} \mathrm{C}$. The weight loss that occurred in this stage was over $15 \%$. This means that the precursors decomposed when heated to produce water and carbon dioxide. The third weight loss up to $400{ }^{\circ} \mathrm{C}$ was negligible. According to the reactions detailed in eqn (1)-(3), the calculated weight losses are $25.96 \%, 22.32 \%$ and $19.41 \%$, consistent with the curves of the TG analysis. Therefore, it can be concluded that the thermal decomposition of $\mathrm{Co}\left(\mathrm{CO}_{3}\right)_{0.5}$ $(\mathrm{OH})_{0.1} \cdot \mathrm{H}_{2} \mathrm{O}, \mathrm{Zn}_{5}\left(\mathrm{CO}_{3}\right)_{2}(\mathrm{OH})_{6}$ and $\mathrm{Ni}(\mathrm{OH})_{2}$ was complete and $\mathrm{Co}_{3} \mathrm{O}_{4}, \mathrm{ZnO}$ and $\mathrm{NiO}$ were formed by the decomposition of the precursors. This also explains how the porous architectures developed. These decomposition reactions are as follows:

$$
\begin{gathered}
\mathrm{Co}\left(\mathrm{Co}_{3}\right)_{0.5}(\mathrm{OH})_{0.1} \cdot \mathrm{H}_{2} \mathrm{O} \stackrel{\Delta}{\longrightarrow} \mathrm{Co}_{3} \mathrm{O}_{4}+\mathrm{H}_{2} \mathrm{O}+\mathrm{CO}_{2} \uparrow \\
\mathrm{Zn}_{5}\left(\mathrm{CO}_{3}\right)_{2}(\mathrm{OH})_{6} \stackrel{\Delta}{\longrightarrow} \mathrm{ZnO}+\mathrm{H}_{2} \mathrm{O}+\mathrm{CO}_{2} \uparrow \\
\mathrm{Ni}(\mathrm{OH})_{2} \stackrel{\Delta}{\longrightarrow} \mathrm{NiO}+\mathrm{H}_{2} \mathrm{O} \uparrow
\end{gathered}
$$

Through the above statement, we have demonstrated the formation process of the metal oxides characterized with large nanopores. In order to further confirm the internal structures of
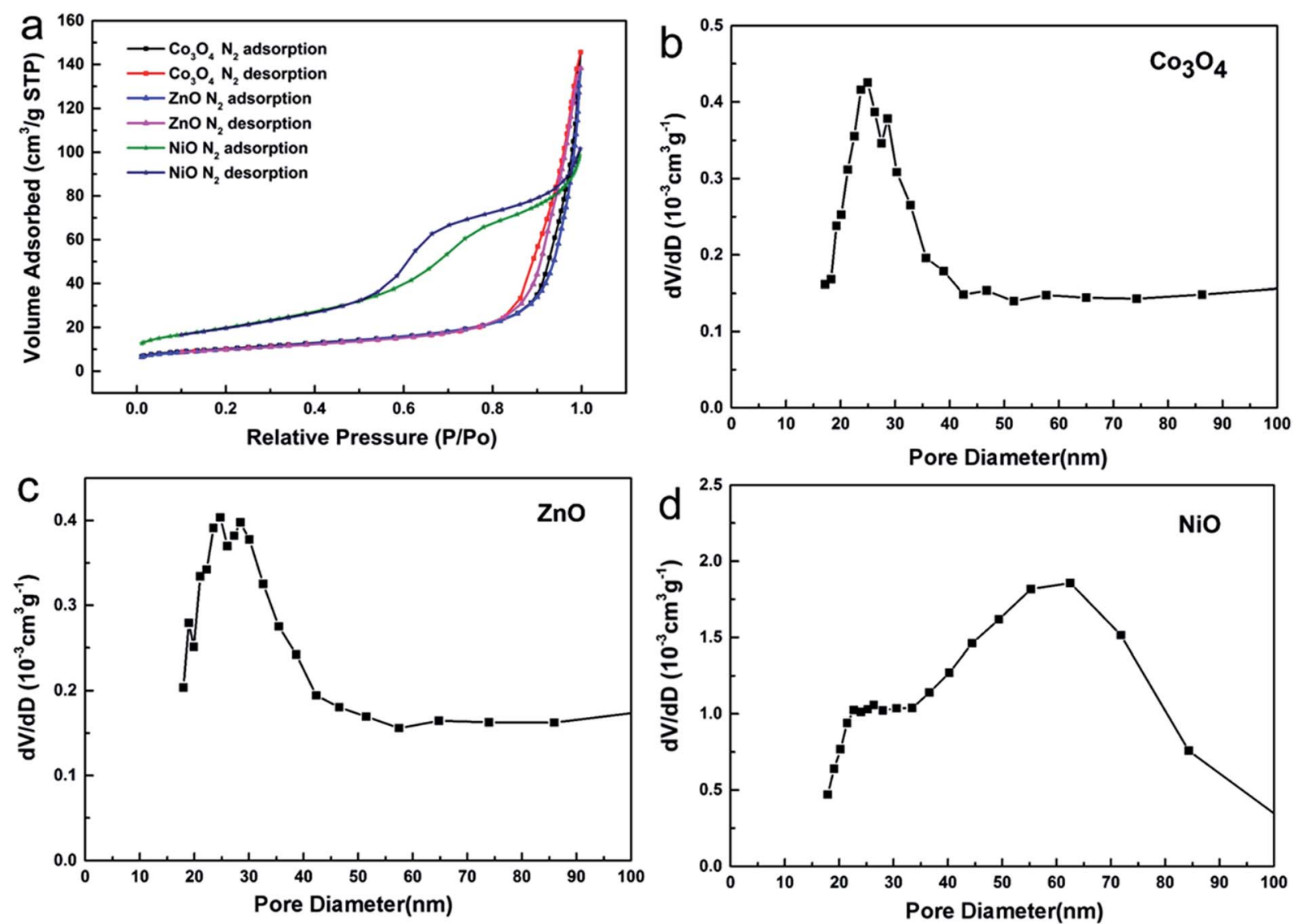

Fig. 4 (a) $\mathrm{N}_{2}$ adsorption-desorption isotherms of the $\mathrm{CO}_{3} \mathrm{O}_{4}$ nanowires, $\mathrm{ZnO}$ nanosheets and $\mathrm{NiO}$ nanosheets. (b-d) The $\mathrm{BJH}$ pore size distribution curves of $\mathrm{CO}_{3} \mathrm{O}_{4}, \mathrm{ZnO}$ and $\mathrm{NiO}$. 
the porous oxides, $\mathrm{N}_{2}$ adsorption-desorption experiments were utilized to explore the architectural properties. As can be observed from Fig. $4 \mathrm{a}$, the $\mathrm{N}_{2}$ adsorption quantity of $\mathrm{Co}_{3} \mathrm{O}_{4}, \mathrm{ZnO}$ and $\mathrm{NiO}$ increased when the relative pressure was raised, which is very common in porous materials. ${ }^{23}$ The calculated results of the BET specific surface area are $35.8 \mathrm{~m}^{2} \mathrm{~g}^{-1}$ for the $\mathrm{Co}_{3} \mathrm{O}_{4}$ porous nanowires, $34.5 \mathrm{~m}^{2} \mathrm{~g}^{-1}$ for the $\mathrm{ZnO}$ porous nanosheets, and $72.8 \mathrm{~m}^{2} \mathrm{~g}^{-1}$ for the NiO porous nanosheets. The pore sizes can be seen from Fig. $4 \mathrm{~b}-\mathrm{d}$, and it is clear that the peaks on the pore size distribution curves are narrow, which shows that the pore sizes are uniform.

\section{Surface modification by Au nanoparticles}

According to some recent studies, the gas-sensing properties of materials are closely related to their morphology, structure and modification with noble-metals. ${ }^{24-28}$ On the basis of the above structures and morphologies, surface modification experiments were carried out using a noble-metal. From Fig. 5, it can be easily seen that $\mathrm{Au}$ nanoparticles are evenly distributed on the surfaces of the three metal oxides and there was no obvious agglomeration (see Fig. S2†). In the TEM images, the Au nanoparticles are highlighted using bright color. The diameters of the $\mathrm{Au}$ nanoparticles are less than $100 \mathrm{~nm}$. For the sake of convenience, the three metal oxides with surface modification will be called $\mathrm{Co}_{3} \mathrm{O}_{4}-\mathrm{Au}, \mathrm{ZnO}-\mathrm{Au}$ and $\mathrm{NiO}-\mathrm{Au}$, in order.

\section{Sensing properties of as-synthesized samples}

As is well known, the sensitivity of a semiconductor metal oxide gas sensor largely depends on the operating temperature.

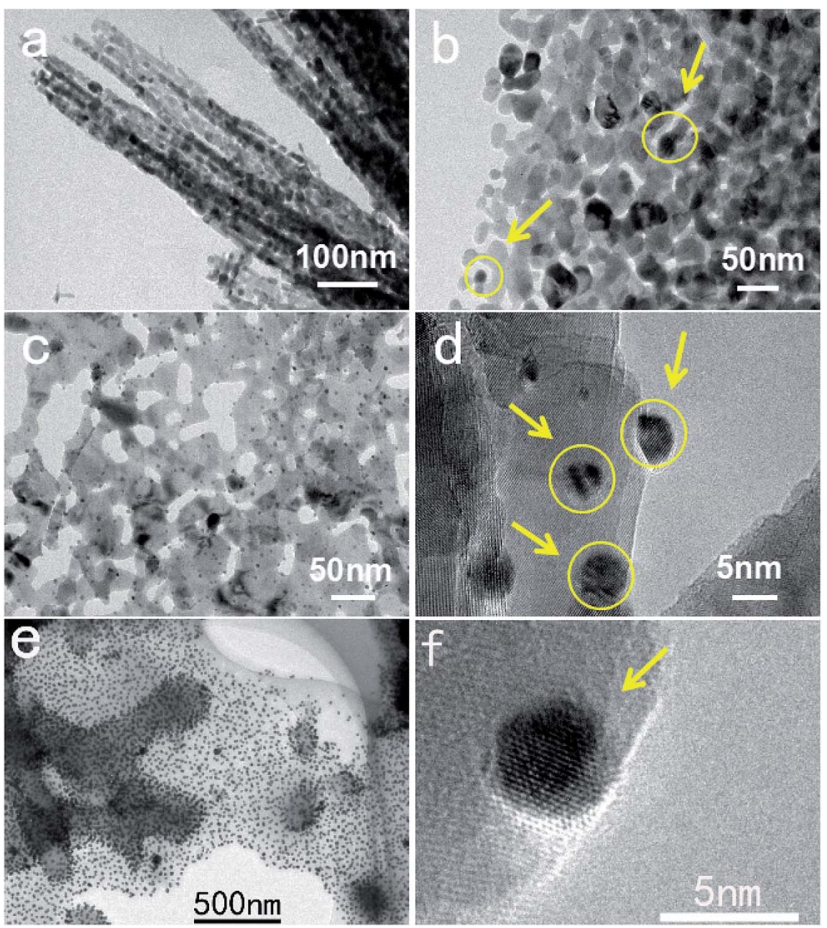

Fig. 5 Typical TEM images of (a and b) $\mathrm{Co}_{3} \mathrm{O}_{4}-\mathrm{Au}$, (c and d) $\mathrm{ZnO}-\mathrm{Au}$, and (e and f) $\mathrm{NiO}-\mathrm{Au}$.
Therefore, finding the best operating temperature is the first step in studying the performance. As depicted in Fig. S3, $\uparrow$ the best operating temperatures are $240{ }^{\circ} \mathrm{C}, 440{ }^{\circ} \mathrm{C}$ and $260{ }^{\circ} \mathrm{C}$ for $\mathrm{Co}_{3} \mathrm{O}_{4}, \mathrm{ZnO}$ and $\mathrm{NiO}$, respectively. Sensitivity, as an important performance indicator of a gas sensor, can be defined as follows:

$$
S=R_{\text {gas }} / R_{\text {air }}
$$

$R_{\text {gas }}$ is the resistance value in the target gas and $R_{\text {air }}$ is the resistance value in air. In this paper, the sensors were used to test the gas sensitivity of common volatile organic compounds like alcohol, acetone, methyl alcohol, formaldehyde and $n$ butanol. From Fig. 6a, we can see that the sensitivities to 100 ppb of VOCs are larger than 1.5. Among the VOCs, the three materials are more sensitive to $n$-butanol than to the other gases. The sensitivity of $\mathrm{Co}_{3} \mathrm{O}_{4}, \mathrm{ZnO}$ and $\mathrm{NiO}$ to $n$-butanol is 5.8, 38.3 and 3.3, respectively. Furthermore, these three kinds of hierarchically porous metal oxide-based sensors have a quick response and recovery to VOCs. When exposed to VOCs, their response and recovery times were mostly less than 25 seconds (Fig. 6b). For example, the recovery time of $\mathrm{Co}_{3} \mathrm{O}_{4}$ to formaldehyde was only 15 seconds and that of $\mathrm{ZnO}$ to acetone was only 7
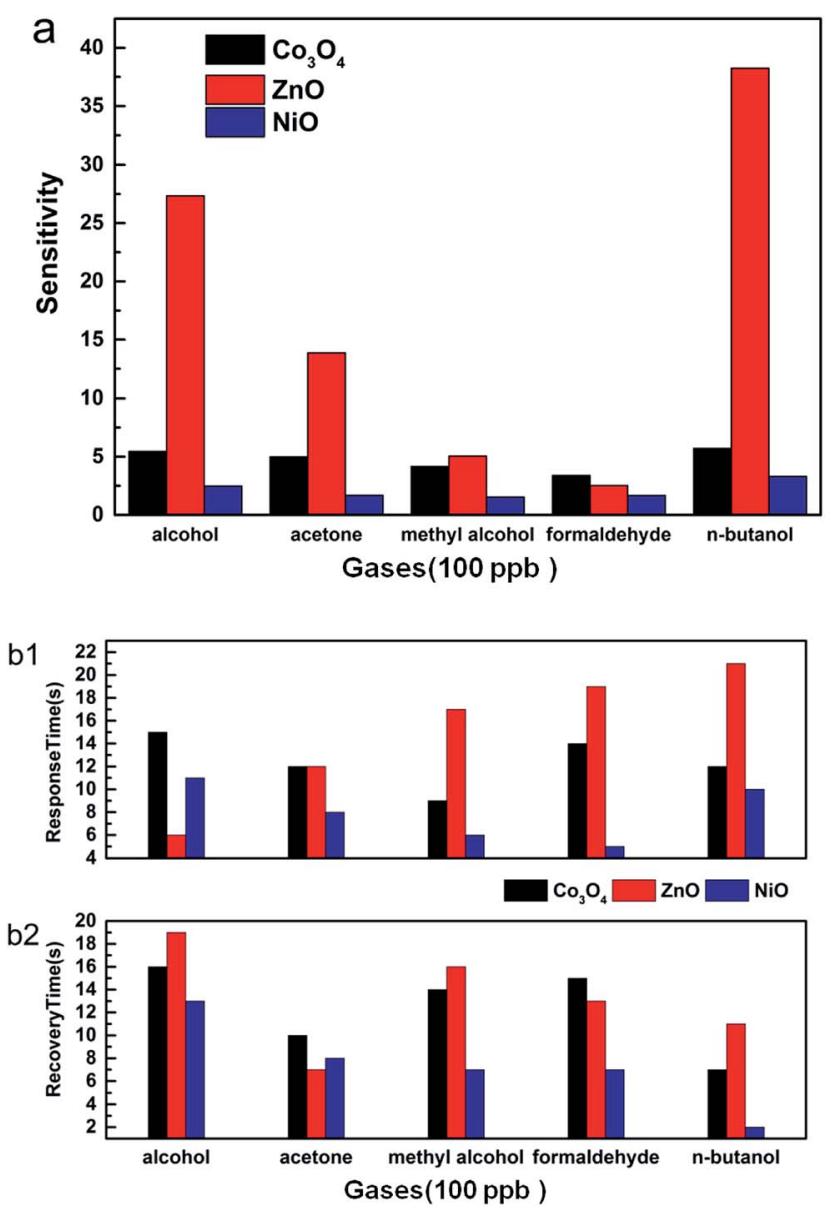

Fig. 6 (a) Gas sensitivities and $\left(b_{1}\right.$ and $\left.b_{2}\right)$ response and recovery times of porous $\mathrm{CO}_{3} \mathrm{O}_{4}$, porous $\mathrm{ZnO}$, and porous $\mathrm{NiO}$. 
seconds. In particular, the response and recovery times of $\mathrm{NiO}$ to formaldehyde were 5 seconds and 7 seconds, respectively. In practice, the lowest detection limit is a significant measure that

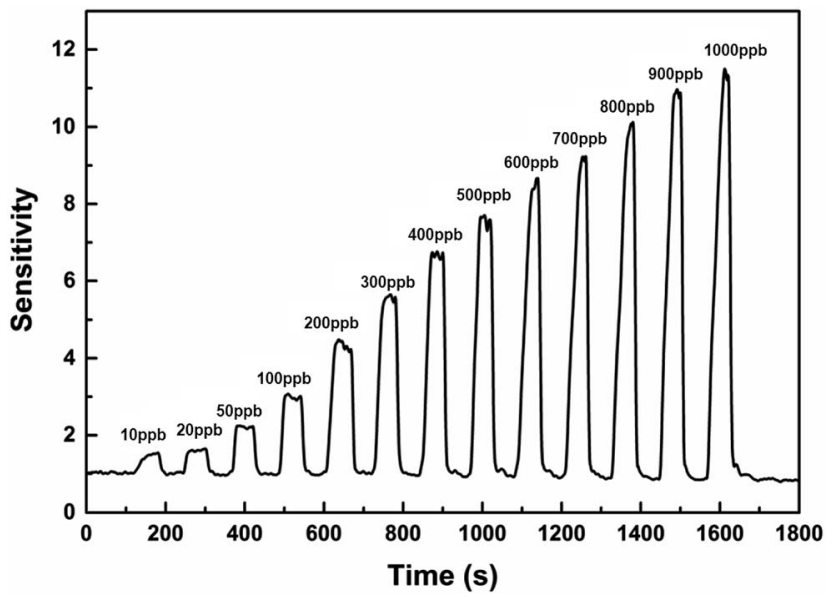

Fig. 7 The detection limits of $\mathrm{ZnO}$ for formaldehyde at room temperature. reflects the capability of a gas sensor. The responses of $\mathrm{ZnO}$ under various concentrations from $15 \mathrm{ppb}$ to $1000 \mathrm{ppb}$ of formaldehyde are displayed in Fig. 7. It is clear that the sensitivity increased with increasing concentration of formaldehyde. The graph also reveals that the lowest detection limit of porous $\mathrm{ZnO}$ is $15 \mathrm{ppb}$ for formaldehyde. According to national and international standards for indoor air quality (IAQ), the highest allowable concentration of formaldehyde is $60 \mathrm{ppb}$; therefore, these hierarchical porous $\mathrm{ZnO}$ nanosheets can fully meet detection requirements.

For the purpose of achieving the best performance due to noble-metal surface modification, experiments to find the optimum loading amount were carried out (Fig. S4†). It can be found that the sensitivity curves show a parabolic trend with increasing Au loading amount in the range of 1-50\%. Apparently, when the Au loading amount is $3 \%$, the sensitivities of $\mathrm{Co}_{3} \mathrm{O}_{4}-\mathrm{Au}$, $\mathrm{ZnO}-\mathrm{Au}$ and $\mathrm{NiO}-\mathrm{Au}$ to VOCs achieve their maximum values.

Fig. 8 shows the increase in sensitivity of the metal oxides before and after the surface modification. When the gas sensors were exposed in an atmosphere of 50 ppb VOCs, it was easy to observe the better performance of the metal oxide containing
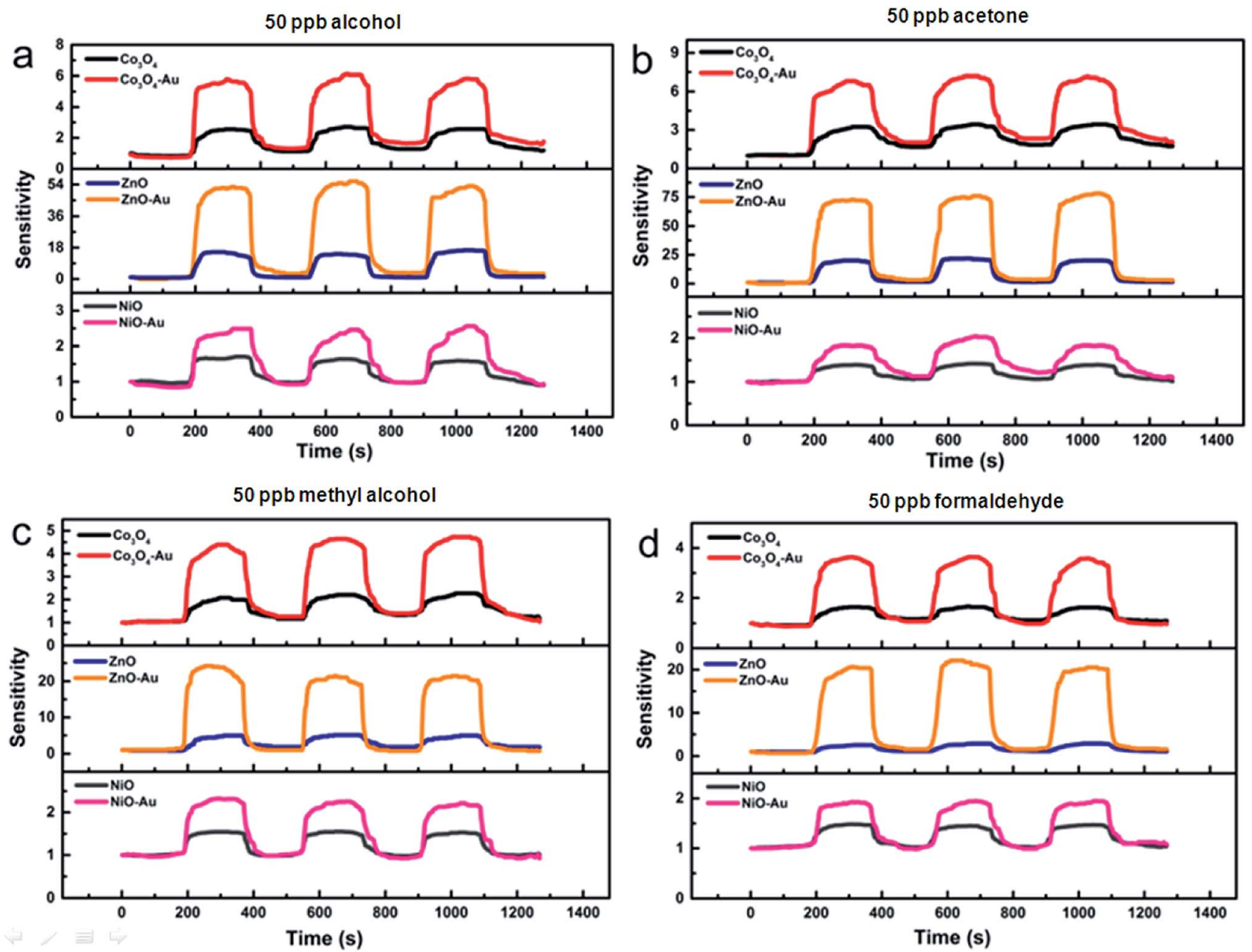

Fig. 8 The sensing responses of $\mathrm{CO}_{3} \mathrm{O}_{4} / \mathrm{Co}_{3} \mathrm{O}_{4}-\mathrm{Au}, \mathrm{ZnO} / \mathrm{ZnO}-\mathrm{Au}$ and $\mathrm{NiO} / \mathrm{NiO}-\mathrm{Au}$ to $50 \mathrm{ppb}$ (a) alcohol, (b) acetone, (c) methyl alcohol, and (d) formaldehyde at each optimum operating temperature. 


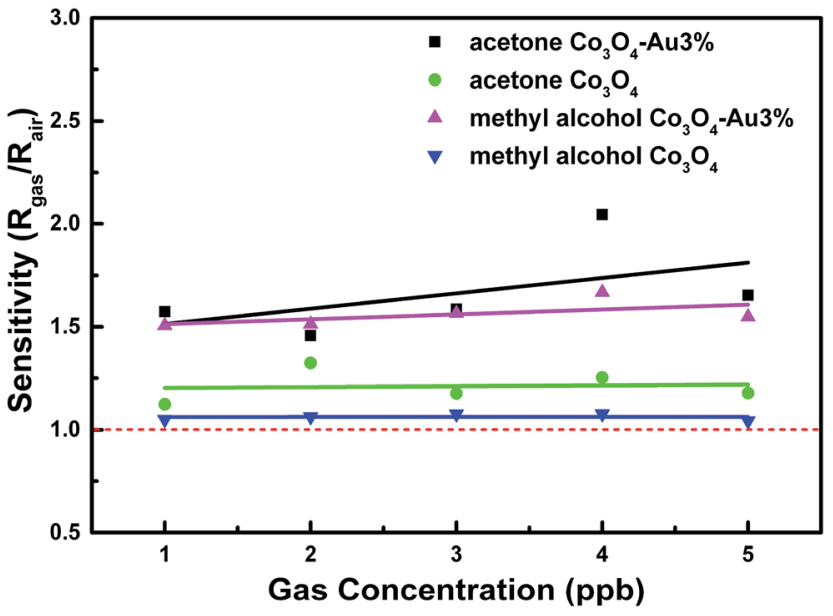

Fig. 9 The sensing responses to 1-5 ppb acetone and methyl alcohol at each optimum operating temperature of $\mathrm{CO}_{3} \mathrm{O}_{4}$ and $\mathrm{CO}_{3} \mathrm{O}_{4}-\mathrm{Au}$.

the optimum Au loading amount. For example, when these gas sensors were in the best working condition, the sensitivities of $\mathrm{ZnO}-\mathrm{Au} / \mathrm{ZnO}$ to $50 \mathrm{ppb}$ alcohol, acetone, methyl alcohol and formaldehyde were 8.4, 4.7, 5.5 and 6.2 times greater, respectively, confirming that the enhancements achieved after surface modification were enormous. After Au modification, the lowest detection limit of porous $\mathrm{ZnO}-\mathrm{Au}$ was as low as $10 \mathrm{ppb}$ for formaldehyde.

In addition to the above measures, the linear relation with the VOC concentration is also a major indicator for the gassensing properties of a material. Based on the best operating temperature and Au loading amount, the sensitivity linearity was recorded when the acetone and methyl alcohol concentration were in the range of 1 to $5 \mathrm{ppb}$. As shown in Fig. 9, with an increase in concentration, the sensitivity of $\mathrm{Co}_{3} \mathrm{O}_{4}$ improved linearly. This reveals that $\mathrm{Co}_{3} \mathrm{O}_{4}$ and $\mathrm{Co}_{3} \mathrm{O}_{4}-\mathrm{Au}$ exhibit great linearity at low gas concentrations and the sensitivity linearity is improved through Au surface modification.

To date, many studies have confirmed the positive effect of noble-metal nanoparticles. ${ }^{29,30}$ The phenomenon of increasing gas sensitivity is also well explained. On one hand, the addition of $\mathrm{Au}$ nanoparticles can lead to the formation of a rich active center, thus it is beneficial for enhancing gas adsorption and increasing the concentration of the reaction. ${ }^{31}$ Meanwhile, adding Au nanoparticles can also reduce the reaction activation energy and increase the reaction rate. ${ }^{32}$ On the other hand, Au at the surface of the metal will participate in the oxygen adsorption reaction..$^{33}$ This leads to the formation of more $\mathrm{O}^{-}, \mathrm{O}^{2-}$ and $\mathrm{O}^{2-}$ at the material surface. When the sensors come into contact with gases, the oxygen adsorbed on the surface of the material will react with the gas molecules, leading to more electron transfer. Therefore, this phenomenon will result in a more obvious change in the resistance of gas-sensitive materials. ${ }^{34-37}$

\section{Conclusions}

In summary, hierarchically porous metal oxides with controlled morphology and noble-metal surface modification have been successfully achieved via a facile and general two-step method. According to step one, three hierarchical precursors, namely, $\mathrm{Co}\left(\mathrm{CO}_{3}\right)_{0.5}(\mathrm{OH})_{0.1} \cdot \mathrm{H}_{2} \mathrm{O}, \quad \mathrm{Zn}_{5}\left(\mathrm{CO}_{3}\right)_{2}(\mathrm{OH})_{6}$ and $\mathrm{Ni}(\mathrm{OH})_{2}$, with different morphologies were achieved. After calcination, the corresponding oxides were prepared, which contain many pores densely distributed in their secondary structures. The samples exhibit high response and sensitivity to VOCs, such as alcohol, acetone, methyl alcohol, formaldehyde and $n$-butanol. The lowest detection limit of $\mathrm{ZnO}$ is $10 \mathrm{ppb}$ for formaldehyde. Au surface modification can further enhance the gas-sensing properties of the hierarchically porous oxides. In particular, the signal linearity of $\mathrm{Co}_{3} \mathrm{O}_{4}$ becomes better even when the gas sensors are exposed to a low gas concentration. Thus, the study highlights the obvious advantages of the gas sensors in their operability, convenience, cost consumption and environmental friendliness. It also takes both performance and application into consideration. Therefore, the method presented in this work to construct hierarchically porous architectures has wide application potential in the field of gas sensors and other disciplines.

\section{Acknowledgements}

This research is partly funded by the National Natural Science Foundation of China (51603091, 51472226), the Natural Science Foundation of Jiangsu Province (BK20150505), and the Opening Project of State Key Laboratory of Fire Science (HZ2015-KF07).

\section{Notes and references}

1 J. Zhang, X. H. Liu, G. Neri and N. Pinna, Adv. Mater., 2016, 28, 795-831.

2 G. X. Zhu, H. Xu and Y. Y. Xiao, ACS Appl. Mater. Interfaces, 2012, 4, 744-751.

3 A. Tricoli, M. Righettoni and A. Teleki, Angew. Chem., Int. Ed., 2010, 49, 7632-7659.

4 L. Li, C. M. Zhang and W. Chen, Nanoscale, 2015, 7, 1213312142.

5 H. Zhang, R. Wu, Z. Chen, G. Liu, Z. Zhang and Z. Jiao, CrystEngComm, 2012, 14, 1775-1782.

6 D. Volanti, A. A. Felix and M. Orlandi, Adv. Funct. Mater., 2013, 23, 1759-1766.

7 N. S. Ramgir, P. K. Sharma, N. Datta, M. Kaur, A. Debnath, D. Aswal and S. Gupta, Sens. Actuators, B, 2013, 186, 718.

8 D. W. Chu, Y. P. Zeng, D. L. Jiang and Y. Masuda, Sens. Actuators, B, 2009, 137, 630-636.

9 L. L. Wang, J. N. Deng, Z. Lou and T. Zhang, J. Mater. Chem. A, 2014, 2, 10022-10028.

10 P. Sun, L. You and D. W. Wang, Sens. Actuators, B, 2011, 156, 368.

11 L. L. Wang, Z. Lou and J. A. Deng, ACS Appl. Mater. Interfaces, 2015, 7, 13098-13104.

12 X. Zhou, C. Wang, W. Feng and P. Sun, Mater. Lett., 2014, 120, 5-8.

13 D. Jung, M. Han, J. Kim and G. S. Lee, Nanotechnology, 2014, 12, 18-21. 
14 M. X. Ma, Z. Y. Pan, L. Guo, J. H. Li and Z. Y. Wu, Sci. Bull., 2012, 5, 4019-4023.

15 C. Wang, X. B. Cui, J. Y. Liu, X. Zhou, X. Y. Cheng, P. Sun, X. L. Hu, X. W. Li, J. Zheng and G. Y. Lu, ACS Sens., 2015, 11, 1-8.

16 L. Xu, R. F. Zheng, S. H. Liu, J. Song, J. S. Chen, B. Dong and H. W. Song, Inorg. Chem., 2012, 51, 7733-7740.

17 N. A. Joy, M. I. Nandasiri, P. H. Rogers, W. Jiang, T. Varga, S. V. N. T. Kuchibhatla, S. Thevuthasan and M. A. Carpenter, Anal. Chem., 2012, 84, 5025-5034.

18 J. Wang, P. Yang and X. W. Wei, ACS Appl. Mater. Interfaces, 2015, 1, 1-28.

19 J. Zhang, D. W. Zeng, Q. Zhu, J. J. Wu, K. Xu, T. G. Liao, G. Z. Zhang and C. S. Xie, J. Phys. Chem., 2015, 12, 1-24.

20 P. Muthukumaran, C. Sumathi, J. Wilson, C. Sekar and S. G. Leonardi, Sens. Lett., 2014, 1, 17-23.

21 N. V. Long, T. Teranishi, Y. Yang, M. T. Cao and Y. Cao, Neoreviews, 2015, 7, 159-172.

22 S. Asuha, B. Suyala and S. Zhao, Mater. Chem. Phys., 2011, 129, 483-487.

23 Y. Min and Q. M. Gao, Microporous Mesoporous Mater., 2011, 143, 230-235.

24 J. Ding, J. W. Zhu, P. C. Yao, J. Li, H. P. Bi and X. Wang, Ind. Eng. Chem. Res., 2015, 9, 12-24.

25 D. Peeters, D. Barreca, G. Carraro, E. Comini, A. Gasparotto, C. Maccato, C. Sada and G. Sberveglieri, J. Phys. Chem. C, 2014, 118, 11813-11819.
26 N. Ma, K. Suematsu, M. Yuasa and K. Shimanoe, ACS Appl. Mater. Interfaces, 2015, 7, 15618-15625.

27 S. Vallejos, P. Umek, T. Stoycheva, F. Annanouch, E. Llobet, X. Correig, P. D. Marco, C. Bittencourt and C. Blackman, Adv. Funct. Mater., 2013, 23, 1313-1322.

28 D. Buso, M. Post, C. Cantalini, P. Mulvaney and A. Martucci, Adv. Funct. Mater., 2008, 18, 3843-3849.

29 S. Wang, B. Xiao, T. Yang, P. Wang, C. Xiao, Z. Li, R. Zhao and M. Zhang, J. Mater. Chem. A, 2014, 2, 6598.

30 S. G. Babu and R. Karvembu, Ind. Eng. Chem. Res., 2011, 50, 9594.

31 Z. P. Li, Q. Q. Zhao, W. L. Fan and J. H. Zhan, Nanoscale, 2011, 3, 1646-1652.

32 D. D. Li, J. Hu, R. Q. Wu and J. G. Lu, Nanotechnology, 2010, 21, 485502.

33 I. D. Kim, A. Rothschild, B. H. Lee, D. Y. Kim, S. M. Jo and H. L. Tuller, Nano Lett., 2006, 6, 2009-2013.

34 S. M. Zhu, D. Zhang, J. J. Gu, J. Q. Xu, J. P. Dong and J. L. Li, J. Nanopart. Res., 2010, 12, 1389.

35 O. Safonova, T. Neisius, A. Ryzhikov, B. Chenevier, A. Gaskov and M. Labeau, Chem. Commun., 2005, 41, 5202-5204.

36 P. Hu, N. Han, X. Zhang, M. S. Yao, Y. B. Cao, A. H. Zuo, G. Yang and F. L. Yuan, J. Mater. Chem., 2011, 21, 1427714284 .

37 A. Kolmakov, D. O. Klenov, Y. Lilach, S. Stemmer and M. Moskovits, Nano Lett., 2005, 5, 667. 